\title{
Saludo a Juan Pablo Izquierdo A Salute to Juan Pablo Izquierdo
}

\author{
por \\ León Schidlowsky \\ Compositor, Tel Aviv, Israel \\ leon@schidlowsky.com
}

\begin{abstract}
Este artículo pasa revista a los contactos entre Juan Pablo Izquierdo y el compositor chileno-israelí León Schidlowsky cuando ambos residían en Chile hace cincuenta años. Hans Loewe, un violonchelista germano-chileno, fue también parte del grupo. Continuaron los contactos posteriormente en Israel, país en que León Schidlowsky reside en la actualidad, cuando Izquierdo se hizo cargo de la dirección musical de los Festivales Testimonium que se realizan en Jerusalén.

Palabras clave: Instituto de Extensión Musical, Hans Loewe, Hermann Scherchen, Festivales Testimonium, Israel; Pontificia Universidad Católica de Chile, Departamento de Música.

This article deals with the musical and personal contacts of Juan Pablo Izquierdo with León Schidlowsky, a Chilean-Israeli composer. These contacts started some fifty years ago when both Izquierdo and Schidlowsky resided in Chile. Hans Loewe, a German-Chilean cellist, was also part of this group. Afterwards they resumed their contact in Israel, where Schidlowsky presently resides, when Izquierdo became musical director of the Testimonium Israel Festival in Jerusalem.

Key words: Instituto de Extensión Musical, Hans Loewe, Hermann Scherchen, Testimonium Israel Festival, Pontificia Universidad Católica de Chile, Music Department.
\end{abstract}

Escribir algunas palabras sobre Juan Pablo Izquierdo no ha sido una tarea fácil. El tiempo urde su propio juego y a veces es necesario recordar a pesar de la neblina del pasado.

Conocí a Juan Pablo hace más o menos cincuenta años en Chile, en la casa de Juan Adolfo Allende Blin. Fue un encuentro corto, pleno de vivencias que todavía están presentes en mi memoria. En diferentes épocas cultivamos una amistad que ha permanecido en el tiempo a pesar de los diferentes espacios en que nuestras respectivas vidas se han ido desarrollando.

Ambos abandonamos Chile en los años 50 para iniciar estudios en el extranjero. Ambos regresamos a Chile cargados con nuevas herramientas que nos colocaron a la vanguardia del arte musical contemporáneo. Chile vivía aún en un círculo concéntrico de unidades de valores musicales que ya habían sido sobrepasados de acuerdo con nuestras visiones sobre la música.

Cada uno en su campo desarrolló su propio camino. Además las circunstancias hicieron posible llevar a cabo iniciativas que nos unían en el aspecto artístico musical. Pero debo hacer una pausa de carácter personal. Junto a nosotros un 
tercer miembro se acercó a nuestros ideales, era un personaje también músico de ascendencia europea. ¿Qué sucedía? Los tres poseíamos algo más en común que era nuestro día de nacimiento: 21 de julio. Cada cual en su respectivo año. Este tercer miembro era Hans Loewe (Q.E.P.D.), primer violonchelo de la Orquesta Sinfónica de Chile.

Poco a poco se desarrolló en cada uno un destino profesional que nos permitía intercambiar ideas en el campo de la música. Juan Pablo Izquierdo, como director de orquesta, Hans Loewe como intérprete solista y quien escribe estas líneas como compositor. Cada uno desarrolló su propia ruta y llegó el momento en que descubrimos en profundidad el valor que cada uno ofrecía en su campo.

Juan Pablo Izquierdo se destacó desde el inicio como un director de orquesta que traía consigo una actitud ética frente a la música, tanto tradicional como contemporánea. Alumno de Hermann Scherchen, uno de los maestros y pedagogos más importantes de nuestro tiempo, era natural entonces que Izquierdo pudiera desarrollarse en esta dirección.

Tanto Hans Loewe como quien escribe estas líneas vislumbramos entonces el camino que Juan Pablo Izquierdo iniciaba. No fue fácil para él escalar los pesados andamios de una vieja tradición junto a un arte de dirigir que involucraba un profundo análisis de la obra elegida para su ejecución. Este aspecto lo logré confirmar años más tarde cuando me desempeñaba como director del Instituto de Extensión Musical (IEM). Invité entonces a Chile al maestro Hermann Scherchen y pude intercambiar opiniones al respecto con el famoso director alemán.

Más tarde viajó Juan Pablo Izquierdo a los Estados Unidos para participar en el Concurso Dimitri Mitropoulos, en el que fue galardonado con el primer premio, lo que le permitió iniciar una carrera internacional.

De regreso a Chile Juan Pablo Izquierdo pasó a ser director del Departamento de Música de la Universidad Católica. Ambos utilizamos nuestros cargos, él desde la Universidad Católica, yo desde el IEM, con el propósito de dar a conocer tanto la música tradicional como la música contemporánea, inclusive aquella creada en Chile.

Pero al margen de todo este proceso deseo volver al aspecto personal de la labor de Izquierdo.

Su carrera fue brillante. Realizó diferentes conciertos, tanto en Chile, los Estados Unidos o Europa, en los que los valores musicales eran desarrollados con la intensidad y la entrega que las obras interpretadas exigían. Cabe recalcar que esta posición Izquierdo la ha mantenido hasta nuestros días. Esta responsabilidad que él mismo adquirió implica una ética y una estética, con un carácter y énfasis propio. Sean estas obras de Schoenberg y la Escuela de Viena, Varèse, Xenakis, Nono o en su defecto un Bach, Beethoven, Brahms o un Mahler. Además no debo olvidar su interpretación de un Revueltas, Ginastera o un Villa-Lobos. Todavía debo además nombrar como experiencia personal el interés de Izquierdo por la obra de los creadores nacionales. Él ha dado a conocer en varios países del mundo obras musicales escritas por compositores chilenos.

Como corolario se debe agregar que Izquierdo se hizo cargo de los Festivales Testimonium en los años 80-90 del siglo XX, efectuados en Israel. El propósito 
de estos festivales era la ejecución de obras comisionadas por el Festival, cuya temática debía estar enraizada en la historia del pueblo judío. Así fueron invitados compositores de la talla de Stockhausen, Kagel, Xenakis, Dallapiccola, como también compositores israelíes. Aquí demostró Juan Pablo Izquierdo su generosidad tanto artística como humana y su valor como director en la ejecución de las respectivas obras.

Posteriormente Juan Pablo ha mantenido una constante pasión por el arte musical de nuestro tiempo, a lo que se debe agregar la edición fonográfica de sus interpretaciones.

Si es verdad que la amistad sobrevive las penurias de la vida, para mi regocijo esta amistad cobija a su vez la admiración respetuosa del suscrito por la labor de este músico chileno a través de los años.

Quiero poner fin a estas acotaciones parciales con una cita que creo retrata la actitud de Juan Pablo Izquierdo para con la música: "la vida decisiva de los hombres no se realiza solo en lo real y en lo concreto, lo más profundo es a lo que ata el mortal su alma: es su ilusión, es su ensueño" (Jacob Wasserman). Gracias, Juan Pablo. 